University of Nebraska - Lincoln

DigitalCommons@University of Nebraska - Lincoln

\title{
Identification of differentially expressed genes in sorghum (Sorghum bicolor) brown midrib mutants
}

\author{
Li Yan \\ Shandong University, yanli@ima.umn.edu \\ Shuwei Liu \\ Shandong University, liusw@sdu.edu.cn \\ Shuangyi Zhao \\ Shandong University \\ Yali Kang \\ Shandong University \\ Duoxiang Wang \\ Shandong University \\ See next page for additional authors
}

Follow this and additional works at: https://digitalcommons.unl.edu/usdaarsfacpub

Yan, Li; Liu, Shuwei; Zhao, Shuangyi; Kang, Yali; Wang, Duoxiang; Gu, Tongwei; Xin, Zhanguo; Xia, Guangmin; and Huang, Yinghua, "Identification of differentially expressed genes in sorghum (Sorghum bicolor) brown midrib mutants" (2012). Publications from USDA-ARS / UNL Faculty. 1134.

https://digitalcommons.unl.edu/usdaarsfacpub/1134

This Article is brought to you for free and open access by the U.S. Department of Agriculture: Agricultural Research Service, Lincoln, Nebraska at DigitalCommons@University of Nebraska - Lincoln. It has been accepted for inclusion in Publications from USDA-ARS / UNL Faculty by an authorized administrator of DigitalCommons@University of Nebraska - Lincoln. 


\section{Authors}

Li Yan, Shuwei Liu, Shuangyi Zhao, Yali Kang, Duoxiang Wang, Tongwei Gu, Zhanguo Xin, Guangmin Xia, and Yinghua Huang 


\title{
Identification of differentially expressed genes in sorghum (Sorghum bicolor) brown midrib mutants
}

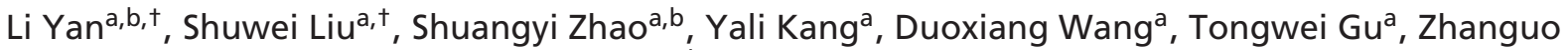 \\ $\mathrm{Xin}^{\mathrm{c}}$, Guangmin $\mathrm{Xia}^{\mathrm{a}, *}$ and Yinghua Huang ${ }^{\mathrm{b}, *}$ \\ ${ }^{a}$ The Key Laboratory of Plant Cell Engineering and Germplasm Innovation, Ministry of Education, School of Life Sciences, Shandong University, Jinan \\ 250100, P.R. China \\ bUSDA-ARS Plant Science Research Laboratory, Stillwater, OK 74075, USA \\ 'Plant Stress and Germplasm Development Unit, USDA-ARS, Lubbock, TX 79415, USA
}

\author{
Correspondence \\ *Corresponding authors, \\ e-mail: xiagm@sdu.edu.cn \\ e-mail: yinghua.huang@ars.usda.gov
}

Received 22 November 2011;

revised 15 March 2012

doi:10.1111/j.1399-3054.2012.01646.x

\begin{abstract}
Sorghum, a species able to produce a high yield of biomass and tolerate both drought and poor soil fertility, is considered to be a potential bioenergy crop candidate. The reduced lignin content characteristic of brown midrib (bmr) mutants improves the efficiency of bioethanol conversion from biomass. Suppression subtractive hybridization combined with cDNA microarray profiling was performed to characterize differential gene expression in a set of $13 \mathrm{bmr}$ mutants, which accumulate significantly less lignin than the wildtype plant BTx623. Among the 153 differentially expressed genes identified, 43 were upregulated and 110 downregulated in the mutants. A semiquantitative RT-PCR analysis applied to 12 of these genes largely validated the microarray analysis data. The transcript abundance of genes encoding L-phenylalanine ammonia lyase and cinnamyl alcohol dehydrogenase was less in the mutants than in the wild type, consistent with the expectation that both enzymes are associated with lignin synthesis. However, the gene responsible for the lignin synthesis enzyme cinnamic acid 4-hydroxylase was upregulated in the mutants, indicating that the production of monolignol from L-phenylalanine may involve more than one pathway. The identity of the differentially expressed genes could be useful for breeding sorghum with improved efficiency of bioethanol conversion from lignocellulosic biomass.
\end{abstract}

\section{Introduction}

The development of sources of renewable energy is driven by the depletion of global fossil fuel reserves, a steady increase in the price of oil and gas and the need to reduce net emissions of carbon dioxide into the atmosphere. Plant biomass is a promising source of renewable energy (Schmer et al. 2008). Currently, the majority of biofuel (in particular ethanol) is derived from the fermentation of maize starch or sugarcane juice (Li et al. 2008), so it has been recognized that further increases in the supply of these particular sources of energy will compete with food production for arable land. Thus, the next generation of biofuels should be targeted at plants not only

Abbreviations - ATPC1, ATP synthase gamma chain 1; bmr ,brown-midrib; $C 4 \mathrm{H}$, cinnamic acid 4-hydroxylase; CAD, cinnamyl alcohol dehydrogenase; CCR, cinnamoyl-CoA reductase; COMT, caffeic acid O-methyltransferase; EMB2753, embryo-defective 2753; ER, endoplasmic reticulum; EST, expressed sequence tag; GUN4, genomes uncoupled 4; HLH, helix loop helix; HMG, high mobility group protein; PAL, I-phenylalanine ammonia lyase; SSH, suppression subtractive hybridization.

\footnotetext{
${ }^{\dagger}$ These authors equally contributed to this work.
} 
suitable for producing sufficient biomass for converting to biofuels but also able to grow on marginal land.

Sorghum (Sorghum bicolor) has some potential to be developed for this purpose. Being a C4 plant, its photosynthetic efficiency is higher than that of C3 species (Carpita and McCann 2008). Current cultivars are bred for grain, sugar or fodder production, and all types are in principle suitable as a source of bioenergy, either via the hydrolysis and fermentation of starch from grain sorghum, the fermentation of simple sugars from sweet sorghum, or the hydrolysis and fermentation of polysaccharides of forage sorghum. More importantly, sorghum is particularly tolerant of low soil moisture and poor nutrient availability (Corredor et al. 2009). In drought-prone, low fertility soils, it can be cropped successfully for up to 2 years before the fertility of the soil becomes so depleted that there is a need for replenishment.

Cellulose, hemicellulose and lignin are the primary components of the plant cell wall, and so dominate the lignocellulosic biomass (Jung and Ni 1998). The cellulose molecule is formed by the interlinkage of glucose moieties, mostly through glycosidic bonds; the hemicellulose polysaccharide is composed of various pentose and hexose moieties, and in planta aggregates the cellulosic fibers into microfibrils. Lignin is a complex polyphenylpropanoid that stiffens the cell wall, and also is associated with resistance to a range of biotic stresses (Del Rio et al. 2007). The current cost of converting lignocellulosic biomass to ethanol is commercially uncompetitive, mainly because the polysaccharides are embedded in a lignin matrix, which impedes the enzymatic hydrolysis process required to generate the necessary monosaccharides. It is the removal of lignin that is the most costly step in the ethanol conversion process (Wyman et al. 2005, Li et al. 2008). Thus, one way to achieve a more cost-effective conversion process would be breed cultivars that accumulate less lignin, while increasing the amount of cellulose present. The brownmidrib (bmr) mutants identified in maize, sorghum and millet fit this requirement (Cherney et al. 1991). They are recognized by the brown pigmentation of their leaf midrib and stalk pith, which first becomes apparent at the four- to six-leaf stage. Biochemical analysis has shown that the lignin content in their cell walls and vascular tissues is less than that in the wild type (Barrière et al. 2004). In particular, Porter et al. (1978) demonstrated that the lignin content of the mature stem of the sorghum $b m r$ mutant was about half that in the wild type, whereas its leaf lignin content was just one quarter. Similarly, in maize, a $50 \%$ higher yield of fermentable sugars was obtainable from the stover of $b m r$ mutants than was possible from wild-type stover (Vermerris et al. 2007).
Little is known regarding the location of the various bmr mutations within the lignin synthesis pathway, which is both complex and highly regulated. The maize bm 3 mutant has been associated with lesions in the gene encoding caffeic acid $O$-methyltransferase (COMT) (Vignols et al. 1995), whereas the bm1 mutation affects the expression of cinnamyl alcohol dehydrogenase (CAD) (Halpin et al. 1998). In sorghum, the same genes were affected in, respectively, the bmr12 and bmr6 mutants (Bout and Vermerris 2003, Sattler et al. 2009). Here, we describe the identification of differential expression in sorghum bmr mutants, by combining suppression subtractive hybridization ( $\mathrm{SSH}$ ) with cDNA microarray analysis. As well as identifying what genes are differentially expressed, the approach also can help resolve questions related to cell-wall metabolism in sorghum. More generally, these data may be applicable to other lignocellulosic bioenergy crops in which there is a need to improve biomass quality.

\section{Materials and methods}

\section{Plant materials and growth conditions}

The study was based on a comparison between the wild-type sorghum cultivar BTx623 (the variety used to acquire the sorghum genome sequence, see http://www.phytozome.net/sorghum) and 13 ethyl methane sulfonate-mutated $\mathrm{bmr}$ mutants $(b m r, b m r 6$, bmr12, bmr29, bmr30, bmr31, bmr32, bmr33, bmr34, bmr35, bmr36, bmr45 and bmr49) all in a genetic background of BTx623. The bmr mutant lines have been backcrossed to the wild type for several generations to clean the genetic background (Xin et al. 2009). Grain of all 14 lines were sown in potting composite in a greenhouse held at $29^{\circ} \mathrm{C}$ and $60 \%$ relative humidity, and grown under a $14 \mathrm{~h}$ photoperiod up to the five- to seven-leaf stage. The fifth or sixth leaf was snap-frozen in liquid nitrogen and stored at $-80^{\circ} \mathrm{C}$ before being used as a source of RNA. Lignin determinations were made from the leaves of five- and seven-leaf stage seedlings, and from the stem of seven-leaf stage seedlings.

\section{Lignin content determination}

The lignin content of bmr mutants and BTx623 was determined using an improved acetyl bromide procedure. Plant material was ground into a fine powder in liquid nitrogen and freeze-dried for $48 \mathrm{~h}$. About $0.01 \mathrm{~g}$ of powder was rinsed four times with $95 \%$ ethanol and twice with distilled water, dried at $60^{\circ} \mathrm{C}$ and then suspended in $2 \mathrm{ml} 25 \%$ acetylbromide $(\mathrm{v} / \mathrm{v}$ in glacial acetic acid). After a 30-min incubation at $70^{\circ} \mathrm{C}, 0.9 \mathrm{ml}$ 
$2 \mathrm{M} \mathrm{NaOH}$ was added, followed by $3 \mathrm{ml}$ glacial acetic acid and $0.1 \mathrm{ml} 7.5 \mathrm{M}$ hydroxylamine hydrochloride. After centrifuging at $4000 \mathrm{~g}$ for $10 \mathrm{~min}$, the supernatant was diluted 20-fold with glacial acetic acid, and the absorbance determined at $280 \mathrm{~nm}$.

\section{RNA isolation}

Total RNA was isolated from frozen leaf tissue using the TRIzol reagent (Invitrogen, Carlsbad, CA). An equimolar mixture of the RNA extracted from the $13 \mathrm{bmr}$ mutants was taken forward for mRNA purification and reverse transcription. An Oligotex mRNA Midi kit (Qiagen, Valencia, CA) was employed to acquire the mRNA from a 1-mg aliquot of total RNA.

\section{Suppression subtractive hybridization}

A PCR-based cDNA subtraction was carried out using a PCR-Select cDNA Subtraction kit (Clontech, Mountain View, CA). Both a forward (BTx623 as the driver and $b m r$ as the tester) and a reverse (bmr as the driver and BT×623 as the tester) subtraction library was created from $2 \mu \mathrm{g}$ mRNA. The tester cDNA was digested with Rsa I and ligated to adaptors 1 and $2 \mathrm{R}$, and two rounds of hybridization and amplification were performed. The resulting amplicon was cloned into the pJET1.2/blunt vector (Fermentas, Glen Burnie, $\mathrm{MD}$ ) and introduced into Escherichia coli $\mathrm{DH} 5 \alpha$ cells (Invitrogen), which were then cultured overnight in liquid LB medium. A 2- $\mu$ l aliquot of the bacterial culture was taken as the template for a PCR based on the primer pair Nested 1 and 2R, provided in the PCRselect cDNA subtraction kit. Insert sizes were checked by agarose gel electrophoresis, resulting in a set of 6600 recombinant clones carrying inserts in the size range 100-500 bp.

\section{Preparation of the cDNA microarray}

The surplus amplicon of the 6600 recombinant clones was precipitated by the addition of two volumes of ethanol, chilling at $-80^{\circ} \mathrm{C}$ for $1 \mathrm{~h}$ and centrifuging at $17200 \mathrm{~g}$ for $10 \mathrm{~min}$. After washing with $70 \%$ ethanol, the DNA pellet was dissolved in $3 \times$ saline-sodium citrate buffer. The cDNA clones were arrayed in duplicate on two amino-silane-coated slides (Corning Inc., Acton, MA) with each clone spotted three times on each slide. The slides were then rehydrated with hot vapor and held at $80^{\circ} \mathrm{C}$ overnight to immobilize the cDNA.

\section{Probe labeling and hybridization}

cDNA was reverse-transcribed from $100 \mu \mathrm{g}$ total RNA from each of wild-type BTx623 and the bmr mix using an Array 350 hybridization kit (Genisphere, Hatfield, PA). A 100-pg aliquot of two controls (spikes 1 and 3) were added to the total RNA of each sample to allow normalization. During reverse transcription, the BTx623 cDNA was labeled with Cy5 and the bmr mix with $\mathrm{Cy} 3$ and then the two probes were mixed in equimolar amounts. The combined probe was applied to the array and incubated at $42^{\circ} \mathrm{C}$ overnight. The subsequent washing regime followed the manufacturer's recommendations.

\section{Microarray scanning and data analysis}

The slides were analyzed using a ScanArray Express scanner (Perkin-Elmer, San Jose, CA). A linear normalization based on the signal intensities of the internal controls (spikes 1 and 3) spotted on the slide was performed with the aid of GenePix Pro v4.0 software (Axon Instrument, Union City, CA). Pre-processing of the normalized microarray data was performed according to Park et al. (2006). Two independent hybridizations were performed. cDNAs showing an intensity ratio $\geq 2$ were considered to be differentially expressed and taken forward for sequencing on an $\mathrm{ABI} 3730 \mathrm{DNA}$ sequencer (Applied Biosystems, Foster City, CA). After the removal of vector sequence, the sequence set was used as a BLAST query against the GenBank database (http://www.ncbi.nlm.nih.gov).

\section{Semi-quantitative RT-PCR analysis}

A 2- $\mu$ g aliquot of DNase-treated total RNA extracted from the leaf of BTx623 and each of the bmr mutants was reverse-transcribed using an iScript ${ }^{\mathrm{TM}} \mathrm{CDNA}$ synthesis kit (Bio-Rad, Hercules, CA). The subsequent PCR comprised an initial denaturation of $95^{\circ} \mathrm{C} / 4 \mathrm{~min}$, followed by $25-28$ cycles of $95^{\circ} \mathrm{C} / 30 \mathrm{~s}, 53^{\circ} \mathrm{C} / 30 \mathrm{~s}$, $72^{\circ} \mathrm{C} / 40 \mathrm{~s}$ and a final extension of $72^{\circ} \mathrm{C} / 5 \mathrm{~min}$. Cycle number was optimized for each target gene, and at least three technical replicates per target gene were analyzed. The resulting amplicons were visualized in EtBr-stained 1\% agarose gels following electrophoresis.

\section{Results}

\section{Lignin content of the bmr mutants}

As 5 of the 13 mutants grew very poorly, lignin determination was restricted to 8 of them. Each mutant 
accumulated significantly less lignin than the wild type did, although the extent of the reduction varied from mutant to mutant, and also was dependent on the developmental stage of the seedlings (Fig. 1). The bmr34 mutant contained the least lignin in the leaf at the fiveleaf stage (26.8\% less than the wild type), whereas that of the other mutants reduced about $11-17 \%$ compared with the wild-type BTx623 except bmr6 (Table 1). In seven-leaf stage seedlings, the leaf lignin content in bmr36 and bmr32 was, respectively 37.5 and $28.6 \%$ lower than the wild type, and the stem lignin content was reduced, respectively, 27.6 and $29.1 \%$. The lignin content in the other mutants was reduced $9-16 \%$ at this stage except bmr35 (Table 1).
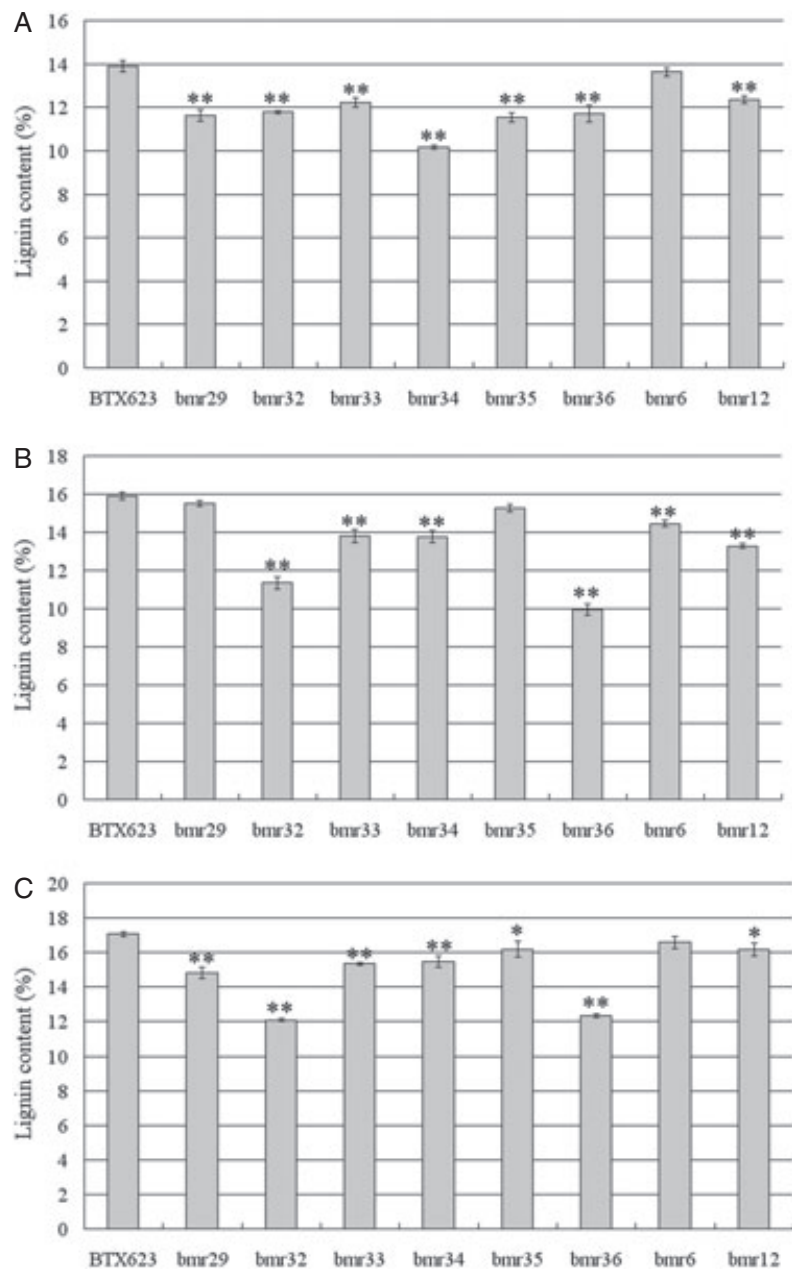

Fig. 1. Lignin content of eight bmr mutants and wild-type BTx623. (A) Lignin content in the leaf of five-leaf stage seedlings; (B) lignin content in the leaf of seven-leaf stage seedlings; (C) lignin content in the stem of seven-leaf stage seedlings. All data given in the form mean \pm SD. ${ }^{*}$ and ${ }^{* *}$ represent significant differences determined by ANOVA at $P<0.05$ and $P<0.01$, respectively.

\section{Identification of differentially expressed genes}

Insert size in the 6600 recombinant clones selected from the forward and reverse subtraction libraries lay in the range of $100-500 \mathrm{bp}$ (Fig. 2). The cDNA microarray analysis revealed that among these, 356 (5.4\%) experienced differential expression (based on a criterion of a minimum of a twofold difference between the wild-type and the bmr mutant bulk. Sequencing of these clones produced 210 non-redundant sequences, of which 153 showed significant homology to genes of known function; 43 of these were upregulated in the bmr mutants and the remainder were downregulated. At the protein level, it was possible to classify the gene products of the 153 genes into 11 functional groups, namely metabolism, photosynthesis, genetic information processing, stress response, protein fate, signal transduction, transport, lignin synthesis, cell processes and mobility, development and regulation, and others (Tables 2 and 3, Fig. 3).

The most abundant group was metabolism, which included 28 downregulated and 19 upregulated genes. Among the 17 differentially expressed genes associated with photosynthesis, 16 were downregulated in the bmr mutants (Tables 2 and 3). These included three genes associated with carbon fixation, four with photosystem I, four with photosystem II and one each with antenna pigment and electron transfer. The single gene upregulated in the mutants encoded a component of the light-harvesting complex. Nine genes associated with development and regulation were downregulated in the mutants, which included those encoding cytochrome P450 78A9 (CYP78A9), ATP synthase gamma chain 1 (ATPC1), histone-binding protein RBBP4, genomes uncoupled 4 (GUN4) protein, RelA/SpoT domain containing protein, seed maturation protein PM23, embryo-defective 2753 (EMB2753) and two senescence-associated proteins (Tables 2 and 3).

Most of those associated with lignin synthesis and protein fate were downregulated in the mutants. In particular, these included genes encoding the three enzymes L-phenylalanine ammonia lyase (PAL), cinnamyl alcohol dehydrogenase (CAD7) and nicotianamine aminotransferase $\mathrm{A}$; however, the gene encoding cinnamic acid 4-hydroxylase $(\mathrm{C} 4 \mathrm{H})$ was upregulated (Tables 2 and 3). Eleven genes involved in protein fate were downregulated in the mutants, which included those encoding DNAJ-related Chaperone protein, DNAJ heatshock N-terminal domain-containing protein, HSP91, HSP101, ubiquitin-protein ligase, ubiquitin-specific peptidase 54, C13 endopeptidase NP1 precursor, peptidase M48 family protein, aspartic proteinase, ATP-dependent Clp protease adaptor protein ClpS family protein and 


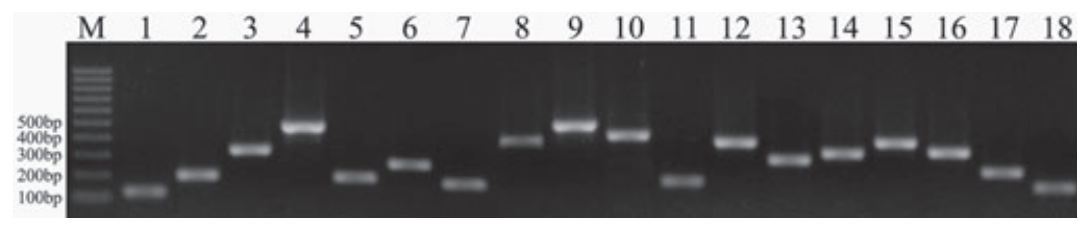

Fig. 2. PCR analysis of clones developed from SSH libraries. M: DNA size marker. Lanes 1-18 illustrate the insert present in each of 18 clones.

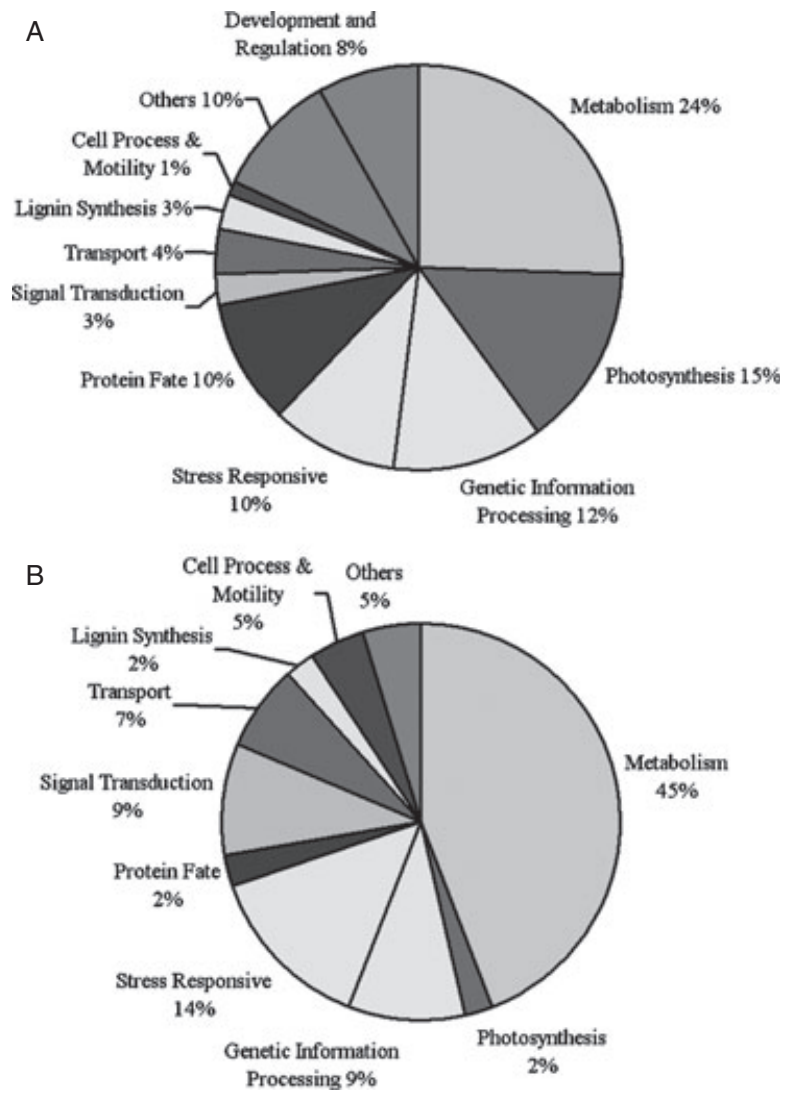

Fig. 3. Functional grouping of the differentially expressed genes in the sorghum bmr mutants. (A) Downregulated genes; (B) upregulated genes.

an ORMDL family protein. Only one gene-encoding prolyl endopeptidase was found to be upregulated in the mutants (Tables 2 and 3).

For the genetic information processing category, a total of 17 genes were obtained and 13 of them showed downregulated expression in the $b m r$ mutants, which included those encoding $5^{\prime}-3^{\prime}$ exoribonuclease (XRN3), basal transcription factor complex subunit-related protein, translation initiation factor SUI1, translation initiation factor-5, 5.8S ribosomal RNA rhizome 2 (RHIZ2), $40 S$ ribosomal protein S7 (RPS7A), $40 S$ ribosomal protein S8 (RPS8B), two peptidylprolyl isomerase and high mobility group (HMG) protein. The four upregulated genes involved in genetic information processing encoding RAP2, diphosphonucleotide phosphatase, Scarecrow-like protein and a bHLH domain containing protein, respectively (Tables 2 and 3). Seventeen proteins responsive to stress were obtained, of which 11 genes showed repressed expression whereas 6 showed enhanced expression in the bmr mutants (Tables 2 and $3)$. For the signal transduction and transport category, seven differentially expressed genes were obtained for each of the two categories (Tables 2 and 3).

\section{Expression pattern of candidate genes}

Semi-quantitative RT-PCR was applied to 12 of the putatively differentially expressed genes (Fig. 4). Seven of these, namely BSSS, CYP78A9, GlyT, PAL, HMG, SUI1 and SDR, were downregulated in the bmr mutants, whereas the other five $(C 4 H, C y t A D, G l y H, b H L H$ and $R A P 2)$ were upregulated. Among the former group, the RT-PCR analysis demonstrated that CYP78A9, PAL, $H M G$ and $S D R$ were repressed in most of the mutants, although the extent of the repression in some of the mutants was only slight. BSSS, GlyT and SUI1 were downregulated in between five and seven of the mutants, with their transcription level remaining indistinguishable from wild type in the remainder (Fig. 4). Among the five upregulated genes, the transcription of $C 4 H, b H L H$ and RAP2 was substantially enhanced in at least five of the mutants, whereas $\mathrm{GlyH}$ was upregulated in only

Table 1. Relative reduction in lignin content of the eight bmr mutants compared with wild-type BTx623 (\%).

\begin{tabular}{|c|c|c|c|c|c|c|c|c|}
\hline & bmr29(\%) & bmr32 (\%) & bmr33 (\%) & bmr34 (\%) & bmr35 (\%) & bmr36 (\%) & bmr6 (\%) & bmr12 (\%) \\
\hline Leaf of 5-leaf stage & 16.3 & 15.3 & 12.1 & 26.8 & 17.0 & 15.8 & 1.9 & 11.1 \\
\hline Leaf of 7-leaf stage & 2.5 & 28.6 & 13.1 & 13.4 & 4.0 & 37.5 & 9.1 & 16.4 \\
\hline Stalk of 7-leaf stage & 13.1 & 29.1 & 10.1 & 9.4 & 5.1 & 27.6 & 2.8 & 5.2 \\
\hline
\end{tabular}


Table 2. Downregulated genes in the bmr mutants.

\begin{tabular}{|c|c|c|c|}
\hline Clone & Homology & Log 2 of signal ratio & E-value \\
\hline \multicolumn{4}{|l|}{ Metabolism } \\
\hline P2-B09 & Ribulose-1,5-bisphosphate carboxylase/oxygenase large subunit & -2.607 & $1.00 \mathrm{E}-131$ \\
\hline $\mathrm{P} 1-\mathrm{H} 12$ & Formamidase & -2.246 & $2.00 E-88$ \\
\hline P4-C10 & Nine-cis-epoxycarotenoid dioxygenase 4 (NCED4) & -2.069 & $3.00 E-69$ \\
\hline P2-G09 & Lipoxygenase 2 (LOX2) & -2.002 & $1.00 E-69$ \\
\hline P3-B10 & 4-Alpha-glucanotransferase (GluT) & -1.957 & $3.00 \mathrm{E}-167$ \\
\hline P2-E10 & Alanine-glyoxylate aminotransferase (AGT) & -1.954 & $5.00 E-32$ \\
\hline $\mathrm{P} 1-\mathrm{A} 06$ & Carbonic anhydrase & -1.823 & $1.60 \mathrm{E}-36$ \\
\hline $\mathrm{P} 2-\mathrm{C0} 6$ & Glyceraldehyde-3-phosphate dehydrogenase B subunit & -1.786 & $8.00 \mathrm{E}-66$ \\
\hline P4-D11 & Cysteine protease & -1.479 & 0 \\
\hline $\mathrm{P} 4-\mathrm{H} 10$ & Glyceraldehyde-3-phosphate dehydrogenase (GADPH) & -1.418 & 0 \\
\hline P3-A10 & Uridylyltransferase-related & -1.360 & $2.00 E-73$ \\
\hline P3-B05 & GDS2631 record; anaerobic carbohydrate metabolism & -1.288 & 0 \\
\hline P2-F03 & 1-Aminocyclopropane-1-carboxylate synthase & -1.277 & $3.00 E-22$ \\
\hline P4-B02 & Pyridoxine biosynthesis 1 (PDX1) & -1.272 & $3.00 E-53$ \\
\hline P3-F09 & Adenosylmethionine decarboxylase family protein & -1.235 & $6.00 E-77$ \\
\hline P3-C01 & Ferrochelatase & -1.210 & $6.00 E-93$ \\
\hline P3-C10 & Albino or pale green mutant 1 (APG1) & -1.141 & $1.00 E-35$ \\
\hline P3-G02 & Nicotinamidase 1 (NIC 1) & -1.098 & $1.00 \mathrm{E}-15$ \\
\hline P3-G07 & Lipoxygenase & -1.090 & $1.00 E-14$ \\
\hline P3-E04 & Cysteine-type peptidase & -1.085 & $8.00 E-26$ \\
\hline P3-H08 & Short-chain dehydrogenase/reductase family protein (SDR) & -1.078 & $4.00 E-52$ \\
\hline P4-A03 & Glycosyl transferase family 17 protein (GlyT) & -1.074 & $7.00 E-55$ \\
\hline P3-H09 & 6-phosphogluconate dehydrogenase2 & -1.074 & $1.00 \mathrm{E}-119$ \\
\hline P4-B11 & Glutathione transferase 20 & -1.074 & $9.00 \mathrm{E}-33$ \\
\hline P4-D07 & Aldo/keto reductase family protein & -1.035 & $5.00 E-56$ \\
\hline P3-B08 & CP12 domain-containing protein 1 (CP12-1) & -1.032 & $8.00 E-26$ \\
\hline P3-E12 & Fructose-bisphosphate aldolase & -1.020 & $2.00 E-38$ \\
\hline $\mathrm{P} 1-\mathrm{C} 03$ & Carbonic anhydrase & -0.985 & $2.00 E-28$ \\
\hline \multicolumn{4}{|c|}{ Photosynthesis } \\
\hline P1-G05 & Photosystem II subunit O-2 (PSBO-2) & -2.150 & $6.00 E-93$ \\
\hline P1-C08 & 23 kDa polypeptide of photosystem II & -1.973 & $1.00 E-49$ \\
\hline P4-D08 & Pyruvate orthophosphate dikinase (PPDK) & -1.758 & $1.00 \mathrm{E}-136$ \\
\hline P2-D04 & Chlorophyll $a / b$ binding protein & -1.754 & $4.00 E-37$ \\
\hline P2-B01 & Photosynthetic electron transfer C (PETC) & -1.682 & $5.00 E-37$ \\
\hline P1-E07 & Photosystem I light harvesting complex gene 4 (LHCA4) & -1.628 & $1.00 E-31$ \\
\hline P1-B12 & Photosystem I reaction center subunit VI & -1.516 & $8.00 E-07$ \\
\hline P4-F3 & PGR5-Like B & -1.478 & $2.00 \mathrm{E}-129$ \\
\hline P1-C01 & Photosystem II type II chlorophyll a/b binding protein & -1.420 & $3.00 E-82$ \\
\hline P1-F02 & Phosphoenolpyruvate carboxylase & -1.374 & $1.00 E-11$ \\
\hline P1-G09 & Photosystem I N subunit 1 & -1.344 & $1.00 E-43$ \\
\hline P1-H09 & Chlorophyll a/b-binding apoprotein CP24 precursor & -1.275 & $6.00 E-57$ \\
\hline P2-E03 & Photosystem II light harvesting complex gene 1.5 & -1.169 & $1.00 E-32$ \\
\hline P1-D02 & Phosphoenolpyruvate involved in C4 photosynthesis & -1.166 & $6.00 E-52$ \\
\hline P4-A10 & Pyruvate orthophosphate dikinase 1 & -1.008 & $9.00 E-54$ \\
\hline$P 1-F 12$ & Plastocyanin & -0.997 & $7.00 E-30$ \\
\hline \multicolumn{4}{|c|}{ Genetic information processing } \\
\hline P1-F08 & Peptidylprolyl isomerase & -2.867 & $4.00 E-137$ \\
\hline P1-A11 & HMG & -2.256 & $1.70 E-35$ \\
\hline P2-F02 & Eukaryotic translation initiation factor-5 & -1.766 & $1.00 E-58$ \\
\hline P1-F01 & 5.8S ribosomal RNA rhizome 2 (RHIZ2) & -1.748 & $1.00 E-55$ \\
\hline $\mathrm{P} 1-\mathrm{B} 02$ & $5^{\prime}-3^{\prime}$ Exoribonuclease (XRN3) & -1.710 & $1.00 E-22$ \\
\hline P3-A6 & Basal transcription factor complex subunit-related & -1.605 & $3.00 E-90$ \\
\hline P3-F7 & Peptidyl-prolyl cis-trans isomerase & -1.227 & $1.00 E-52$ \\
\hline P3-D8 & Variegated 1 (VAR1) & -1.204 & $2.00 E-28$ \\
\hline P4-B4 & 405 ribosomal protein S8 (RPS8B) & -1.118 & $3.00 \mathrm{E}-122$ \\
\hline P4-D6 & 40 S ribosomal protein S7 (RPS7A) & -1.103 & 0 \\
\hline
\end{tabular}


Table 2. Continued

\begin{tabular}{|c|c|c|c|}
\hline Clone & Homology & Log 2 of signal ratio & E-value \\
\hline P3-B7 & Thioredoxin family protein & -1.097 & $2.00 \mathrm{E}-28$ \\
\hline P3-D4 & Embryo-defective 2184 (EMB2184) & -1.062 & $1.00 E-17$ \\
\hline P4-A11 & Eukaryotic translation initiation factor SUI1 & -1.034 & $7.00 E-169$ \\
\hline \multicolumn{4}{|c|}{ Stress responsive } \\
\hline $\mathrm{P} 1-\mathrm{H} 07$ & Protochlorophyllide reductase A & -2.607 & $3.00 E-86$ \\
\hline P2-F06 & Peroxisomal biogenesis factor 11 family protein & -2.231 & 0 \\
\hline $\mathrm{P} 2-\mathrm{CO} 4$ & Bundle sheath strand-specific gene 1 (BSSS) & -1.796 & $4.00 E-64$ \\
\hline P4-E3 & Low expression of osmotically responsive genes 1 (LOS1) & -1.609 & $5.00 E-135$ \\
\hline $\mathrm{P} 4-\mathrm{H} 2$ & Low expression of osmotically responsive genes 2 (LOS2) & -1.437 & $5.00 E-145$ \\
\hline P3-D3 & Plant basic secretory protein (BSP) & -1.332 & $1.00 E-24$ \\
\hline P3-E8 & Light regulated Lir1 family protein, contains InterPro domain & -1.330 & $7.00 \mathrm{E}-27$ \\
\hline $\mathrm{P} 2-\mathrm{H} 01$ & Metallothionein 2A (MT2A) & -1.290 & $1.00 E-58$ \\
\hline P4-C2 & Light regulated Lir1 family protein & -1.288 & $1.00 \mathrm{E}-37$ \\
\hline P3-A5 & Calmodulin-related protein & -1.079 & $4.00 E-19$ \\
\hline P4-D3 & NADPH HC toxin reductase-like protein & -1.030 & $5.00 \mathrm{E}-67$ \\
\hline \multicolumn{4}{|l|}{ Protein fate } \\
\hline P2-D01 & Chaperone protein DNAJ-related & -1.853 & $1.00 \mathrm{E}-69$ \\
\hline P4-F8 & DNAJ heat-shock protein & -1.798 & 8.00E-102 \\
\hline P1-A04 & Ubiquitin-protein ligase & -1.645 & $3.00 \mathrm{E}-122$ \\
\hline P2-B08 & Heat-shock protein 101 & -1.215 & $7.00 E-14$ \\
\hline P4-C5 & Heat-shock protein 91 & -1.635 & 0 \\
\hline P4-B3 & C13 endopeptidase NP1 precursor & -1.534 & $3.00 E-106$ \\
\hline P3-D12 & ATP-dependent Clp protease adaptor protein CIpS & -1.465 & $3.00 \mathrm{E}-101$ \\
\hline P3-E11 & Ubiquitin-specific peptidase 54 & -1.362 & $7.00 \mathrm{E}-128$ \\
\hline P4-A12 & Aspartic proteinase nepenthesin I-like & -1.280 & $3.00 \mathrm{E}-95$ \\
\hline P3-A2 & Peptidase M48 family protein & -1.137 & $3.00 E-37$ \\
\hline P3-H11 & ORMDL family protein & -1.078 & $3.00 E-101$ \\
\hline \multicolumn{4}{|c|}{ Signal transduction } \\
\hline P2-F09 & Adenylate kinase & -1.999 & $5.00 E-38$ \\
\hline P1-D09 & Tyrosine-specific protein phosphatase & -1.840 & $1.00 \mathrm{E}-96$ \\
\hline P1-G06 & MAPK1 & -1.638 & $4.00 \mathrm{E}-117$ \\
\hline \multicolumn{4}{|l|}{ Transport } \\
\hline P2-A08 & $\mathrm{H}^{+}$-transporting two-sector ATPase & -1.830 & $4.00 E-86$ \\
\hline P4-E12 & $\mathrm{Na}^{+} / \mathrm{H}^{+}$antiporter $\mathrm{NhaC}$ & -1.543 & 1.00E-120 \\
\hline $\mathrm{P} 4-\mathrm{H} 8$ & Acclimation of photosynthesis to environment 2 (APE2) & -1.488 & $6.00 \mathrm{E}-134$ \\
\hline P3-E10 & Secretion-associated RAS super family 2 & -1.010 & $2.00 \mathrm{E}-17$ \\
\hline \multicolumn{4}{|c|}{ Lignin synthesis } \\
\hline $\mathrm{P} 4-\mathrm{C} 7$ & Cinnamyl-alcohol dehydrogenase 7 (CAD7) & -1.571 & $8.00 E-38$ \\
\hline P4-C1 & Phenylalanine ammonia-lyase (PAL) & -1.115 & $2.00 E-38$ \\
\hline P3-H5 & Nicotianamine aminotransferase A & -1.036 & $2.00 \mathrm{E}-23$ \\
\hline \multicolumn{4}{|c|}{ Cell process and motility } \\
\hline P4-G4 & Myosin heavy chain & -1.578 & $2.00 \mathrm{E}-175$ \\
\hline \multicolumn{4}{|c|}{ Development and regulation } \\
\hline $\mathrm{P} 4-\mathrm{H} 6$ & Senescence-associated protein & -2.339 & $4.00 E-46$ \\
\hline P2-B04 & RelA/SpoT domain containing protein & -1.693 & $6.00 E-84$ \\
\hline P4-E6 & Seed maturation protein PM23 & -1.648 & $7.00 \mathrm{E}-89$ \\
\hline P3-E3 & Senescence-associated protein & -1.471 & $2.00 E-115$ \\
\hline P3-H10 & EMB2753 & -1.298 & $4.00 E-47$ \\
\hline P2-E04 & Cytochrome P450 78A9 (CYP78A9) & -1.271 & $1.00 E-53$ \\
\hline P1-F04 & Histone-binding protein RBBP4 & -1.728 & $7.00 E-43$ \\
\hline P3-G10 & ATP synthase gamma chain 1 (ATPC 1 ) & -1.618 & $1.00 \mathrm{E}-110$ \\
\hline P4-D9 & GUN4 & -1.298 & 0 \\
\hline \multicolumn{4}{|l|}{ Others } \\
\hline P2-G12 & Esterase/lipase/thioesterase family protein & -1.724 & $7.00 E-129$ \\
\hline P2-A11 & VirB2-interacting protein 2 (BTI2) & -1.620 & $3.00 \mathrm{E}-118$ \\
\hline P4-B1 & Putative thiol-disulphide oxidoreductase DCC & -1.259 & $2.00 \mathrm{E}-65$ \\
\hline P4-A9 & Pentatricopeptide repeat-containing protein (PPR) & -1.230 & $4.00 E-35$ \\
\hline
\end{tabular}


Table 2. Continued

\begin{tabular}{llrr}
\hline Clone & \multicolumn{1}{c}{ Homology } & Log 2 of signal ratio & E-value \\
\hline P3-D9 & Thioredoxin M1 & -1.025 & $1.00 \mathrm{E}-47$ \\
P3-G9 & MTN3 & -1.002 & $4.00 \mathrm{E}-57$ \\
P3-G1 & InterPro domain containing protein & -1.236 & $1.00 \mathrm{E}-27$ \\
P2-G05 & Hypothetical protein, contains InterPro domain & -1.024 & $2.00 \mathrm{E}-88$ \\
P3-F4 & Membrane protein & -1.290 & $5.00 \mathrm{E}-99$ \\
P3-B4 & PB1 domain-containing protein & -1.110 & $3.00 \mathrm{E}-37$ \\
P3-A11 & Peroxisomal membrane protein-related & -1.039 & $3.00 \mathrm{E}-42$ \\
\hline
\end{tabular}

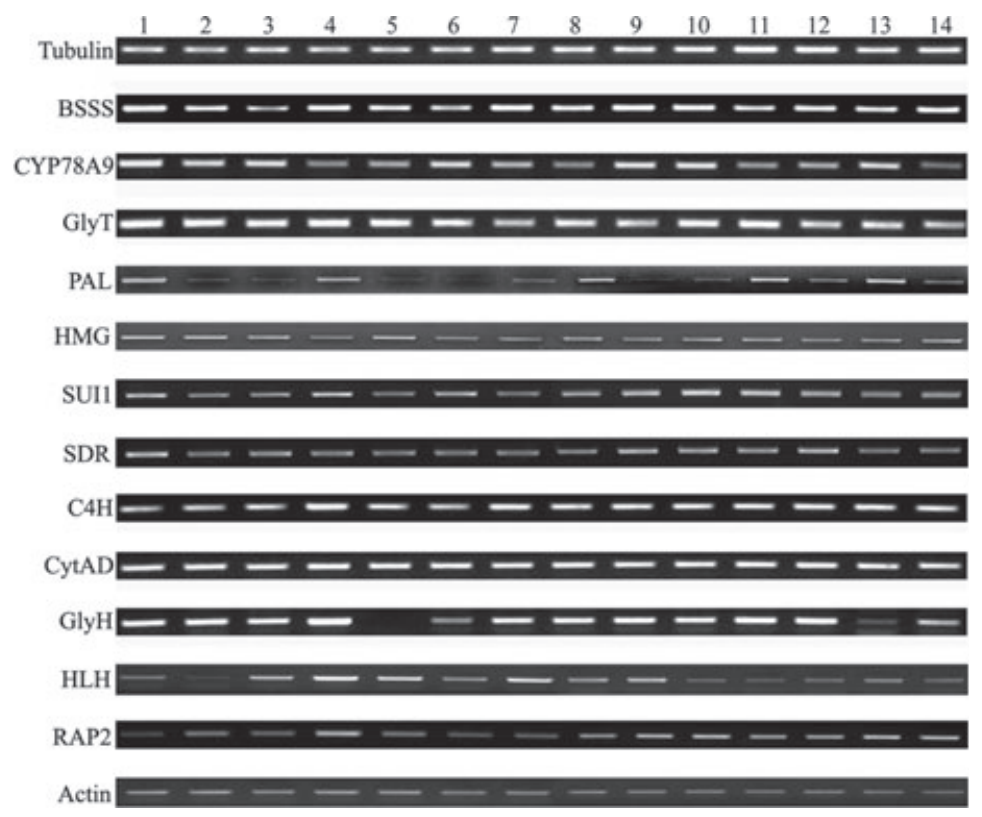

Fig. 4. RT-PCR profiles of a set of genes differentially expressed in the $13 \mathrm{bmr}$ mutants compared with wild-type BTx623. Lane 1: BTx623, lane 2: bmr, lane 3: bmr29, lane 4: bmr30, lane 5: bmr31, lane 6: bmr32, lane 7: bmr33, lane 8: bmr34, lane 9: bmr35, lane 10: bmr36, lane 11: bmr45, lane 12: bmr49, lane 13: bmr6, lane 14: bmr12. BSSS: bundle sheath strand-specific gene 1; CYP78A9, cytochrome P450 78A9; GlyT, glycosyl transferase family 17 protein; HMG, high mobility group protein; SUI1, eukaryotic translation initiation factor SUI1; SDR, short-chain dehydrogenase/reductase family protein; CytAD, cytosolic aldehyde dehydrogenase; GlyH, glycosyl hydrolase family 17 protein; HLH, bHLH domain-containing protein; RAP2, ras family small GTP-binding protein. Tubulin and Actin represent internal loading controls.

three mutants and clearly downregulated in four others. CytAD transcript abundance was marginally raised in five of the mutants. Overall, the RT-PCR outcomes were reasonably consistent with those obtained from the microarray analysis.

\section{Discussion}

Brown midrib mutants are of potential interest in the context of improving bioethanol conversion efficiency, because the lignin content of their vegetative tissue is lower than that of wild-type tissue. Our current understanding of the molecular basis of the mutant phenotype is, however, rather limited. In particular, it will be of relevance to know which of the genes involved in cell-wall metabolism (and their regulation) are affected in the mutants, as this will guide any molecular-based strategy aimed at the genetic improvement of bioenergy crops. In a study of certain maize bm mutants, SSH was combined with microarray analysis to identify 53 differentially expressed genes in bm3 and 32 in all of bm1,bm2 and bm3 (Shi et al. 2006), whereas Guillaumie et al. (2007) showed that, among a set of 144 genes associated with the synthesis of phenylpropanoid and related compounds, 69 were differentially expressed in the young stems of at least one of the four $\mathrm{bm}$ mutants $b m 1-b m 4$. As yet in sorghum, apart from the documented effects on the transcription of the genes encoding COMT and CAD in bmr12 and bmr6 (Bout and Vermerris 2003, Sattler et al. 2009), there is a lack of knowledge of the influence of any of the $b m r$ mutations on the transcriptome. 
Table 3. Upregulated genes in the bmr mutants.

\begin{tabular}{|c|c|c|c|}
\hline Clone & Homology & $\log 2$ of signal ratio & E-value \\
\hline \multicolumn{4}{|l|}{ Metabolism } \\
\hline P4-G6 & Cytosolic aldehyde dehydrogenase (CytAD) & 1.075 & $2.00 \mathrm{E}-60$ \\
\hline P1-G04 & Acyl-coenzyme A oxidase 2 & 1.082 & 4.3 \\
\hline $\mathrm{P} 1-\mathrm{A} 02$ & Fructose-bisphosphate aldolase & 1.096 & $7.30 \mathrm{E}-03$ \\
\hline P4-F9 & Polyamine oxidase 1 & 1.109 & $4.00 E-73$ \\
\hline P4-E9 & Alkaline alpha galactosidase 1 & 1.125 & $4.00 E-35$ \\
\hline P1-E08 & NADP-dependent malic enzyme & 1.128 & 8.8 \\
\hline P4-F2 & Acid phosphatase (class B) family protein & 1.137 & $2.00 E-33$ \\
\hline $\mathrm{P} 1-\mathrm{H} 05$ & Alkaline alpha galactosidase 1 & 1.229 & $3.00 E-50$ \\
\hline P1-B10 & Glutathione S-transferase & 1.241 & $2.00 \mathrm{E}-24$ \\
\hline P2-F04 & Carbonic anhydrase & 1.376 & $3.50 \mathrm{E}-05$ \\
\hline $\mathrm{P} 4-\mathrm{H} 12$ & Nitrate reductase 2 (NIA2) & 1.390 & $3.00 E-14$ \\
\hline P4-G8 & Catalase-3 & 1.417 & $8.00 \mathrm{E}-32$ \\
\hline P4-C9 & Lipoxygenase & 1.475 & $1.00 E-35$ \\
\hline P4-E7 & Inositol-3-phosphate synthase isozyme 2 & 1.710 & $7.00 \mathrm{E}-35$ \\
\hline P4-E4 & Acid phosphatase & 1.804 & $9.00 \mathrm{E}-54$ \\
\hline P4-E1 & Acid phosphatase class B family protein & 2.106 & $3.00 E-42$ \\
\hline P1-C10 & Low phytic acid 1 & 2.264 & $8.00 \mathrm{E}-24$ \\
\hline P2-H09 & Beta-amylase & 2.284 & $3.00 E-23$ \\
\hline P2-A01 & Glycosyl hydrolase family 17 protein $(\mathrm{GlyH})$ & 2.361 & $5.00 \mathrm{E}-25$ \\
\hline \multicolumn{4}{|c|}{ Photosynthesis } \\
\hline P4-A2 & Photosystem I light-harvesting complex gene 6 (LHCA6) & 0.960 & $2.00 E-33$ \\
\hline \multicolumn{4}{|c|}{ Genetic information processing } \\
\hline P2-G04 & Ras family small GTP-binding protein (RAP2) & 0.950 & $2.00 E-35$ \\
\hline $\mathrm{P} 2-\mathrm{H} 02$ & Diphosphonucleotide phosphatase & 1.090 & $1.20 \mathrm{E}-04$ \\
\hline $\mathrm{P} 2-\mathrm{H} 12$ & Scarecrow-like protein & 2.209 & $2.30 \mathrm{E}-02$ \\
\hline P4-E11 & bHLH domain containing protein & 2.683 & $2.00 E-72$ \\
\hline \multicolumn{4}{|c|}{ Stress responsive } \\
\hline P4-C3 & In2-1 protein & 1.045 & $3.00 E-37$ \\
\hline P2-C03 & Early responsive to dehydration 8 & 1.304 & $1.00 \mathrm{E}-33$ \\
\hline P1-D01 & Low molecular mass early light-induced protein & 1.411 & $2.00 E-20$ \\
\hline P1-F06 & Secretory acid phosphatase & 1.669 & $1.50 \mathrm{E}-06$ \\
\hline P1-D08 & Osr40c1 protein & 1.988 & $2.90 \mathrm{E}-09$ \\
\hline P1-A12 & Early light-induced protein precursor & 1.992 & $1.90 \mathrm{E}-16$ \\
\hline \multicolumn{4}{|l|}{ Protein fate } \\
\hline P2-A06 & Prolyl endopeptidase & 1.659 & 4.40E-07 \\
\hline \multicolumn{4}{|c|}{ Signal transduction } \\
\hline P2-G11 & ADP-ribosylation factor & 1.148 & $2.80 \mathrm{E}-03$ \\
\hline P4-G11 & PAP27 & 1.276 & $3.00 E-41$ \\
\hline P3-F10 & PAP10 & 1.763 & $2.00 E-26$ \\
\hline P1-D06 & Purine and other phosphorylases & 2.020 & $2.20 E-06$ \\
\hline \multicolumn{4}{|l|}{ Transport } \\
\hline P2-D07 & Legumain-like protease precursor & 1.042 & $3.40 E-09$ \\
\hline P4-G1 & NOD26-like major intrinsic protein (NIP2-2) & 1.156 & $3.00 E-36$ \\
\hline P4-G3 & Mannitol transporter, putative & 1.177 & $1.00 \mathrm{E}-35$ \\
\hline \multicolumn{4}{|c|}{ Lignin synthesis } \\
\hline P1-D04 & $\mathrm{C} 4 \mathrm{H}$ & 1.768 & 0.037 \\
\hline \multicolumn{4}{|c|}{ Cell process and motility } \\
\hline P4-F6 & TUA6 & 1.573 & $1.00 \mathrm{E}-30$ \\
\hline P2-H08 & Loricrin-like & 2.191 & $3.00 E-45$ \\
\hline \multicolumn{4}{|l|}{ Others } \\
\hline P3-D2 & Harpin-induced 1 domain containing protein & 1.163 & $4.00 E-57$ \\
\hline P3-E7 & Contains InterPro domain & 1.259 & $2.00 E-36$ \\
\hline
\end{tabular}


Here, we have combined SSH and microarray technology in an attempt to identify a set of differentially expressed genes in the bmr mutants. In the conventional SSH method adopted to uncover differentially expressed genes, the contrast is made between a single mutant and the wild type; however, this approach typically results in a large number of candidate sequences, which greatly complicates the process of identifying the key gene(s) responsible for the phenotype. For this reason, we based the SSH libraries on a bulk template formed from 13 independent mutants, reasoning that although this risked concealing some of the genes underlying the phenotype of a subgroup of the mutants, it would help to discover those genes involved in lignin synthesis and expression regulation that might have similar expression patterns in different $b m r$ mutants because all the $b m r$ mutants showed reduced lignin content. The RT-PCR analysis applied to the individual $\mathrm{bmr}$ mutant templates indicated that the genes involved in lignin synthesis showed quite similar expression patterns in the various $\mathrm{bmr}$ mutants, which proved the efficiency of this strategy.

The 153 genes identified by the microarray analysis as being differentially expressed between the bmr mutants and the wild type fell into 11 functional groups. A comparison between maize and sorghum confirms a level of consistency in the functional classification of differentially expressed genes. In both species, most of the genes affected in the brown midrib mutant belong to the categories metabolism, photosynthesis, lignin synthesis, signal transduction and regulation (Shi et al. 2006, Guillaumie et al. 2007). However, there is less consistency in the identity of the individual genes, perhaps reflecting species differences and/or variation in experimental design. Nevertheless, a regular outcome of such expression studies is that metabolism is the most prominent functional group. The synthetic pathway leading to lignin production is rather complex, and includes a large number of precursors and intermediates. Thus, it may not be so surprising to find that any modification (whether quantitative or qualitative) of a single pathway component results in a major alteration in the output of other components in the pathway, or even thanks to cross-talk, of components in other metabolism pathways. An attractive example demonstrated that the reduction in the lignin content and an alteration in its composition induced by the downregulation of the genes encoding either COMT or CAD in switchgrass (Panicum virgatum) raised the rate of sugar released and the production of ethanol, but at the same time had hardly any impact on cell-wall polysaccharide content or structure (Fu et al. 2011a, 2011b).

Among the 17 differentially expressed genes involved in photosynthesis, 16 were downregulated in the bmr mutants. The inhibition of photosynthesis must inevitably result in a reduction in biomass, as indeed was shown by the phenotype of some of the bmr mutants. Whether a negative effect on photosynthesis was causally correlated with the observed reduction in lignin content in the bmr mutants has not been established, but it may be relevant that in tobacco, plants engineered to give reduced levels of both CCR and CAD, the resulting perturbation of the lignin synthesis pathway has been shown to have a measurable impact on other metabolic pathways including photorespiration (Dauwe et al. 2007). Fortunately, it appears that hybrids between the wild type and at least some of the bmr lines do not suffer any yield reduction, even though their lignin content is low and the digestibility of their biomass is high (Sattler et al. 2010).

Given the reduced lignin content of the tissue of $\mathrm{bmr}$ plants, it is hardly surprising that three of the candidates emerging from the analysis were associated with lignin synthesis; a similar outcome was reached with respect to the maize bm1,bm2 and bm3 mutants (Shi et al. 2006, Guillaumie et al. 2007). The RT-PCR-based analysis of PAL expression showed that it was repressed in at least 9 of the $13 \mathrm{bmr}$ mutants. PAL catalyzes the de-amination of L-phenylalanine to form cinnamic acid, and represents the first enzyme in the phenylpropanoid pathway. In $b m 1$, as in the bmr mutants, PAL was downregulated; in contrast, it was substantially upregulated in young $b m 2$ and bm4 plants, even though the lignin content of mature $b m 2$ and $b m 4$ plants is lower than in their wild-type equivalent. $\mathrm{C} 4 \mathrm{H}$ is the second enzyme in this same pathway, and combines with PAL and possibly other phenylpropanoid pathway enzymes to create a metabolic channel through which intermediates can be processed without any diffusion into the cytosol (Achnine et al. 2004). In tobacco, PAL and C4H both colocalize to the endoplasmic reticulum (ER) membrane, and it has been proposed that one role of $\mathrm{C} 4 \mathrm{H}$ is to anchor the channeling complex to the ER (Achnine et al. 2004). Unlike PAL, the transcription of $C 4 H$ was upregulated in most of the sorghum bmr mutants. Transgenic reduction in $\mathrm{C} 4 \mathrm{H}$ and $\mathrm{PAL}$ activity in tobacco both reduces lignin content and changes its composition (Sewalt et al. 1997). PAL is encoded by a multigene family in most of the species investigated by FukasawaAkada et al. (1996). The different transcription profiles of the genes encoding PAL and $\mathrm{C} 4 \mathrm{H}$ between the $\mathrm{bm}$ and bmr mutants, together with their unconformity to lignin content, suggest that the synthesis of monolignol from L-phenylalanine is achieved via more than one route, so that different sets of genes are probably responsible for the reduced lignin content of the $b m$ and $b m r$ mutants. 
A further downregulated lignin synthesis gene in the bmr mutants was $C A D$, the reduced transcription of which was also observed in maize $b m 1$ and sorghum bmr6 (Halpin et al. 1998, Sattler et al. 2009). CAD, a member of the alcohol dehydrogenase superfamily, catalyzes the conversion of hydroxycinnamoyl aldehydes into monolignols, prior to their incorporation into the lignin polymer. Except for $Z m C A D 2$, four $C A D$ genes in $b m 1$ and two in $b m 2$ were also downregulated compared with their wild-type transcription levels (Guillaumie et al. 2007). Reduced CAD activity induced a phenotype similar to brown midrib in transgenic tobacco and poplar (Halpin et al. 1994, Baucher et al. 1996), whereas the transgenic downregulation of $C A D$ is associated with a reduced lignin content and/or changed lignin composition in a range of plant species, resulting in improved sugar release and increased digestibility and pulping efficiency (Halpin et al. 1994, Baucher et al. 1996, 1999, Lapierre et al. 1999, Chen et al. 2003, Fu et al. 2011b). The implication is therefore that a reduction in CAD activity on its own is sufficient to induce the brown midrib phenotype. If this is correct, then $C A D$ would represent a good candidate for manipulating the lignin content of cellulosic plant biomass.

Much progress has been made in understanding the transcriptional regulation of lignin synthesis over the last two decades. Bioinformatics-based analysis of the promoters of lignin synthesis genes has identified the AC element (ACCT/AAA/CC) as a frequent motif, perhaps serving as a shared cis regulatory element driving the coordinated regulation of lignin synthesis (Zhong and Ye 2009). The AC element sequences resemble the maize MYB protein P-binding site (CCT/AACC) (Grotewold et al. 1994) as well as those of a number of MYB proteins encoded by Arabidopsis thaliana, pine and eucalyptus. These transcription factors have emerged as strong candidates for the regulation of lignin synthesis, as their over-expression has been associated with the induction of various lignin synthesis genes, resulting in the ectopic deposition of lignin or secondary wall thickening (Goicoechea et al. 2005, Zhou et al. 2009). In addition to these AC-binding MYBs, some other MYBs have also proven able to activate lignin synthesis genes and cause ectopic lignin deposition when over-expressed (Zhong et al. 2008). None of the differentially expressed sequences in the bmr mutants proved to encode an MYB, but the transcription of a bHLH transcription factor was upregulated in several of them. The heterologous expression of this gene in A. thaliana substantially reduced stem lignin content (data not shown), which suggested that this transcription factor functions as a repressor in the lignin synthesis pathway. The reduction of lignin content in plants achieved via the transgenic downregulation of lignin synthesis genes is often accompanied by abnormal growth and development (Li et al. 2008), but the heterologous expression of the bHLH transcription factor had only a marginal negative effect on biomass accumulation (data not shown). Thus, along with $C A D$, this transcription factor may represent an interesting candidate for the improvement of biomass productivity.

\section{Conclusions}

A number of genes that were differentially expressed in the bmr mutants were identified by comparing the pooled cDNAs of 13 independent $b m r$ mutants with that of the wild type. This set of genes include several strong candidates underlying the $\mathrm{bmr}$ mutations by in silico mapping through comparing the differentially expressed ESTs-enriched genome region with the chromosome location of bmr as a result of the availability of sorghum genome sequences and may provide molecular leads relevant for breeding sorghum cultivars well suited to bioethanol production.

Acknowledgements - This research was funded by the US Department of Agriculture, Agricultural Research Service and the National Key Technology R\&D Program of China (2009BADA7B01). The authors thank Ms. Angie Phillips for her excellent technical support. The US Department of Agriculture (USDA) prohibits discrimination in all its programs and activities on the basis of race, color, national origin, age, disability and, where applicable, sex, marital status, familial status, parental status, religion, sexual orientation, genetic information, political beliefs, reprisal, or because all or part of an individual's income is derived from any public assistance program. (Not all prohibited bases apply to all programs). Persons with disabilities who require alternative means for communication of program information (Braille, large print, audiotape, etc.) should contact USDA's TARGET Center at (202)720-2600 (voice and TDD). To file a complaint of discrimination, write to USDA, Director, Office of Civil Rights, 1400 Independence Avenue, S.W., Washington, D.C. 20250-9410, or call (800)795-3272 (voice) or (202)720-6382 (TDD). USDA is an equal opportunity provider and employer.

\section{References}

Achnine L, Blancaflor EB, Rasmussen S, Dixon RA (2004) Colocalization of L-phenylalanine ammonia-lyase and cinnamate 4-hydroxylase for metabolic channeling in phenylpropanoid biosynthesis. Plant Cell 16: 3098-3109 
Barrière $\mathrm{Y}$, Ralph J, Méchin V, Guillaumie S, Grabber JH, Argillier O, Chabbert B, Lapierre C (2004) Genetic and molecular basis of grass cell wall biosynthesis and degradability. II. Lessons from brown-midrib mutants. C R Biol 327: 847-860

Baucher M, Chabbert B, Pilate G, Van Doorsselaere J, Tollier M-T, Petit-Conil M, Cornu D, Monties B, Van Montagu M, Inze D, Jouanin L, Boerjan W (1996) Red xylem and higher lignin extractability by down-regulating a cinnamyl alcohol dehydrogenase in poplar. Plant Physiol 112: 1479-1490

Baucher M, Bernard-Vailhe MA, Chabbert B, Besle JM, Opsomer C, Van Montagu M, Botterman J (1999) Downregulation of cinnamyl alcohol dehydrogenase in transgenic alfalfa (Medicago sativa L.) and the effect on lignin composition and digestibility. Plant Mol Biol 39: 437-447

Bout S, Vermerris W (2003) A candidate-gene approach to clone the sorghum brown midrib gene encoding caffeic acid O-methyltransferase. Mol Genet Genomics 269: $205-214$

Carpita NC, McCann MC (2008) Maize and sorghum: genetic resources for bioenergy grasses. Trends Plant Sci 13: 415-420

Chen L, Auh CK, Dowling P, Bell J, Chen F, Hopkins A, Dixon RA, Wang ZY (2003) Improved forage digestibility of tall fescue (Festuca arundinacea) by transgenic down-regulation of cinnamyl alcohol dehydrogenase. Plant Biotechnol J 1: 437-449

Cherney JH, Cherney DJR, Akin DE, Axtell JD (1991) Potential of brown-midrib, low-lignin mutants for improving forage quality. Adv Agron 46: 157-198 Corredor DY, Salazar JM, Hohn KL, Bean S, Bean B, Wang D (2009) Evaluation and characterization of forage sorghum as feedstock for fermentable sugar production. Appl Biochem Biotechnol 158: 164-179

Dauwe R, Morreel K, Goeminne G, Gielen B, Rohde A, Van Beeumen J, Ralph J, Boudet A-M, Kopka J, Rochange SF, Halpin C, Messens E, Boerjan W (2007) Molecular phenotyping of lignin-modified tobacco reveals associated changes in cell-wall metabolism, primary metabolism, stress metabolism and photorespiration. Plant J 52: 263-285

Del Rio JC, Marques G, Rencoret J, Martinez AT, Gutierrez A (2007) Occurrence of naturally acetylated lignin units. J Agric Food Chem 55: 5461-5468

Fu CX, Mielenz JR, Xiao XR, Ge YX, Hamilton CY Jr, Rodriguez M, Chen F, Foston M, Ragauskas A, Bouton J, Dixon RA, Wang ZY (2011a) Genetic manipulation of lignin reduces recalcitrance and improves ethanol production from switchgrass. Proc Natl Acad Sci USA 108: $3803-3808$

Fu CX, Xiao XR, Xi YJ, Ge YX, Chen F, Bouton J, Dixon RA, Wang ZY (2011b) Downregulation of cinnamyl alcohol dehydrogenase (CAD) leads to improved saccharification efficiency in switchgrass.

Bioenerg Res 4: 153-164

Fukasawa-Akada T, Kung S, Watson JC (1996)

Phenylalanine ammonia-lyase gene structure, expression, and evolution in Nicotiana. Plant Mol Biol 30: $711-722$

Goicoechea M, Lacombe E, Legay S, Mihaljevic S, Rech P, Jauneau A, Lapierre C, Pollet B, Verhaegen D, Chaubet-Gigot N, Grima-Pettenati J (2005) EgMYB2, a new transcriptional activator from Eucalyptus xylem, regulates secondary cell wall formation and lignin biosynthesis. Plant J 43: 553-567

Grotewold E, Drummond BJ, Bowen B, Peterson T (1994)

The myb-homologous $\mathrm{P}$ gene controls phlobaphene pigmentation in maize floral organs by directly activating a flavonoid biosynthetic gene subset. Cell 76: $543-553$

Guillaumie S, Pichon M, Martinant JP, Bosio M, Goffner D, Barrière $Y$ (2007) Differential expression of phenylpropanoid and related genes in brown-midrib $b m 1, b m 2, b m 3$, and bm4 young near-isogenic maize plants. Planta 226: 235-250

Halpin C, Knight ME, Foxon GA, Campbell MM, Boudet AM, Boon J, Chabbert B, Tollier MT, Schuch W (1994) Manipulation of lignin quality by down regulation of cinnamyl alcohol dehydrogenase. Plant J 6: 339-350

Halpin C, Holt K, Chojecki J, Oliver D, Chabbert B, Monties B, Edwards K, Barakate A, Foxon GA (1998) Brown-midrib maize (bm1)-a mutation affecting the cinnamyl alcohol dehydrogenase gene. Plant J 14: 545-553

Jung HJG, Ni W (1998) Lignification of plant cell walls: impact of genetic manipulation. Proc Natl Acad Sci USA 95: 12742-12743

Lapierre C, Pollet B, Petit-Conil M, Toval G, Romero J, Pilate G, Leple JC, Boerjan W, Ferret V, De Nadai V, Jouanin L (1999) Structural alterations of lignins in transgenic poplars with depressed cinnamyl alcohol dehydrogenase or caffeic acid O-methyltransferase activity have an opposite impact on the efficiency of industrial kraft pulping. Plant Physiol 119: 153-163

Li X, Weng JK, Chapple C (2008) Improvement of biomass through lignin modification. Plant J 54: 569-581

Park SJ, Huang YH, Ayoubi P (2006) Identification of expression profiles of sorghum genes in response to greenbug phloem-feeding using cDNA subtraction and microarray analysis. Planta 223: 932-947

Porter KS, Axtell JD, Lechtenberg VL, Colenbrandu VF (1978) Phenotype fiber composition and in vitro dry matter disappearance of chemically induced brown-midrib (bmr) mutants of sorghum. Crop Sci 18: 205-209

Sattler SE, Saathoff AJ, Haas EJ, Palmer NA, Funnell-Harris DL, Sarath G, Pedersen JF (2009) A 
nonsense mutation in a cinnamyl alcohol

dehydrogenase gene is responsible for the sorghum brown midrib6 phenotype. Plant Physiol 150: 584-595

Sattler SE, Funnell-Harris DL, Pedersen JF (2010) Brown midrib mutations and their importance to the utilization of maize, sorghum, and pearl millet lignocellulosic tissues. Plant Sci 178: 229-238

Schmer MR, Vogel KP, Mitchell RB, Perrin RK (2008) Net energy of cellulosic ethanol from switchgrass. Proc Natl Acad Sci USA 105: 464-469

Sewalt VJH, Ni W, Blount JW, Jung HC, Masoud SA, Howles PA, Lamb C, Dixon RA (1997) Reduced lignin content and altered lignin composition in transgenic tobacco down-regulated in expression of L-phenylalanine ammonia-lyase or cinnamate 4-hydroxylase. Plant Physiol 115: 41-50

Shi C, Koch G, Ouzunova M, Wenzel G, Zein I, Lübberstedt T (2006) Comparison of maize brown-midrib isogenic lines by cellular UV-microspectrophotometry and comparative transcript profiling. Plant Mol Biol 62: 697-714

Vermerris W, Saballos A, Ejeta G, Mosier NS, Ladisch MR, Carpita NC (2007) Molecular breeding to enhance ethanol production from corn and sorghum stover. Crop Sci 47: 142-153

Vignols F, Rlgau J, Torres MA, Capellades M, Puigdomènech $P$ (1995) The brown midrib3 (bm3) mutation in maize occurs in the gene encoding caffeic acid O-methyltransferase. Plant Cell 7: 407-416 Wyman CE, Dale BE, Elander RT, Holtzapple M, Ladisch MR, Lee YY (2005) Coordinated development of leading biomass pretreatment technologies. Bioresource Technol 96: 1959-1966

Xin Z, Wang ML, Burow GB, Burke JJ (2009) An induced sorghum mutant population suitable for bioenergy research. Bioenerg Res 2: 10-16

Zhong RQ, Ye ZH (2009) Transcriptional regulation of lignin biosynthesis. Plant Signal Behav 4: 1028-1034

Zhong RQ, Lee C, Zhou J, McCarthy RL, Ye ZH (2008) A battery of transcription factors Involved in the regulation of secondary cell wall biosynthesis in Arabidopsis. Plant Cell 20: 2763-2782

Zhou J, Chan L, Zhong R, Ye ZH (2009) MYB58 and MYB63 are transcriptional activators of the lignin biosynthetic pathway during secondary cell wall formation in Arabidopsis. Plant Cell 21: 248-266 